\title{
Longitudinal Behaviour of Embedded Rails
}

\author{
Z. Major \\ Széchenyi István University, Department of Transport Infrastructure \\ Egyetem tér 1, 9026 Győr, Hungary \\ Phone: +36 96503038 \\ e-mail: majorz@sze.hu
}

\begin{abstract}
The longitudinal behaviour of embedded rails significantly differs from that of ballasted and slab track with direct rail fastening. As the ambient temperature rises and falls, rails expand and contract, imposing stresses on the channel and the embedding compound. In this article the author presented the creation of a method that makes the calculation and the checking of embedded rails simpler and becomes closer to everyday engineering mentality. The author's design process includes an analysis of displacement and normal forces along the rail axis.
\end{abstract}

Keywords: embedded rail, longitudinal behaviour, breathing length of ERS

\section{Introduction}

The dilatational behaviour of embedded rails significantly differs from that of ballasted and slab track with direct rail fastening [1]. While the firstly flexible resistance is typical of the order of $\sim 10 \mathrm{~mm}$ displacement, in the second and the third cases after a relatively small displacement $(\leq 2 \mathrm{~mm})$ the linear flexible period is followed by an ideally plastic period [2].

This latter behaviour can be modelled with software that enable non-linear calculation (providing spring stiffness and limit force), and in practical calculation the flexible period can be ignored and the plastic ballast resistance can be applied in well-known formulas $[3,4]$.

In Fig. 1 there are force-displacement diagrams valid for ballasted tracks and slab track with direct rail fastening according to Hungarian standard MSZ EN 1991-2:2006 $[5]$. 


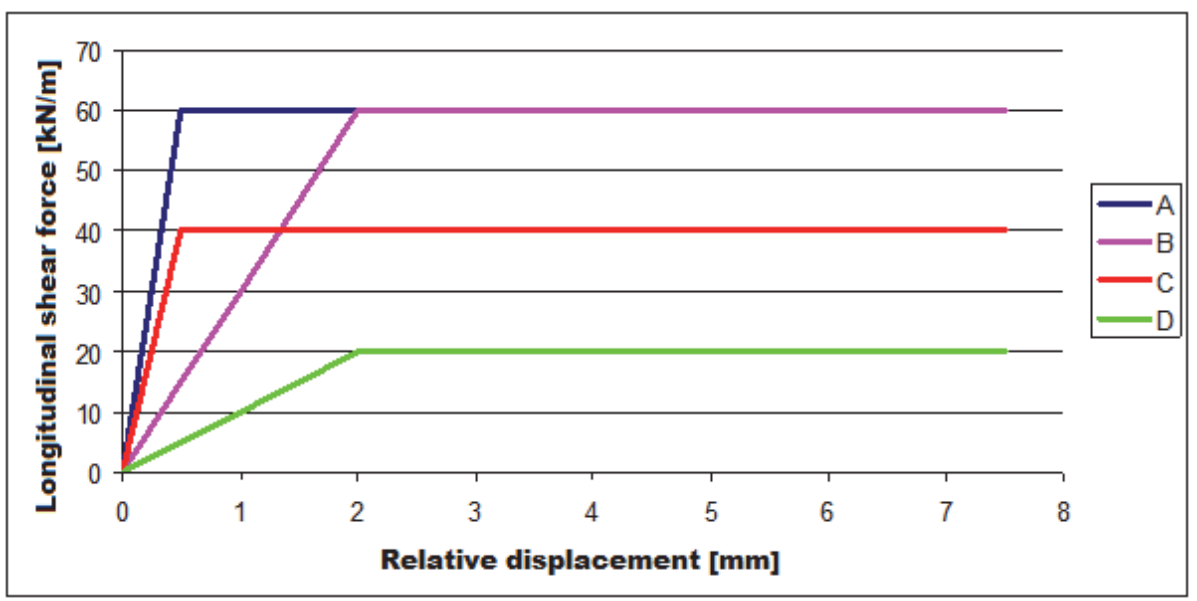

Figure 1. Value of shear resistance in case of ballasted tracks and slab track with direct rail fastening [5]

Note: Fig. 1 is applied to 2 rails!

Table 1. Features of bilinear spring characteristics [6,7]

\begin{tabular}{|c|c|c|c|}
\hline \multirow{2}{*}{ Sign } & \multirow{2}{*}{ Name } & Spring constant & Limit force \\
\hline & & {$[\mathrm{kN} / \mathrm{m} / \mathrm{m}]$} & {$[\mathrm{kN} / \mathrm{m}]$} \\
\hline A & Rail fastening on loaded track & 120,000 & 60 \\
\hline $\mathrm{B}$ & Ballast resistance on loaded track & 30,000 & 60 \\
\hline $\mathrm{C}$ & Rail fastening on unloaded track & 80,000 & 40 \\
\hline $\mathrm{D}$ & $\begin{array}{c}\text { Ballast resistance on unloaded } \\
\text { track }\end{array}$ & 10,000 & 20 \\
\hline
\end{tabular}

The two different kinds of dilatational behaviour (flexible and plastic) show a significant difference when the Figures of dilatational forces and rail end movements are compared. The figures show the behaviour of a $60 \mathrm{E} 1$ rail in case of a $45^{\circ} \mathrm{C}$ temperature change. $10[\mathrm{kN} / \mathrm{m} /$ rail $]$ value as plastic shear resistance was applied, and the embedded rail with the value of $5,000[\mathrm{kN} / \mathrm{m} / \mathrm{m} / \mathrm{rail}]$ was described. When the length of the breathing period was established, $0.01 \mathrm{~mm}$ displacement as a limit condition was set and not complete stillness [8].

The modulus of elasticity of the rail is $206,000\left[\mathrm{~N} / \mathrm{mm}^{2}\right]$, the value of the linear heat expansion factor is $1.2 * 10^{-5}\left[1 /{ }^{\circ} \mathrm{C}\right]$.

Figures 2-5 describe the changes of dilatational forces and the evolving displacement along the length of the rail. 


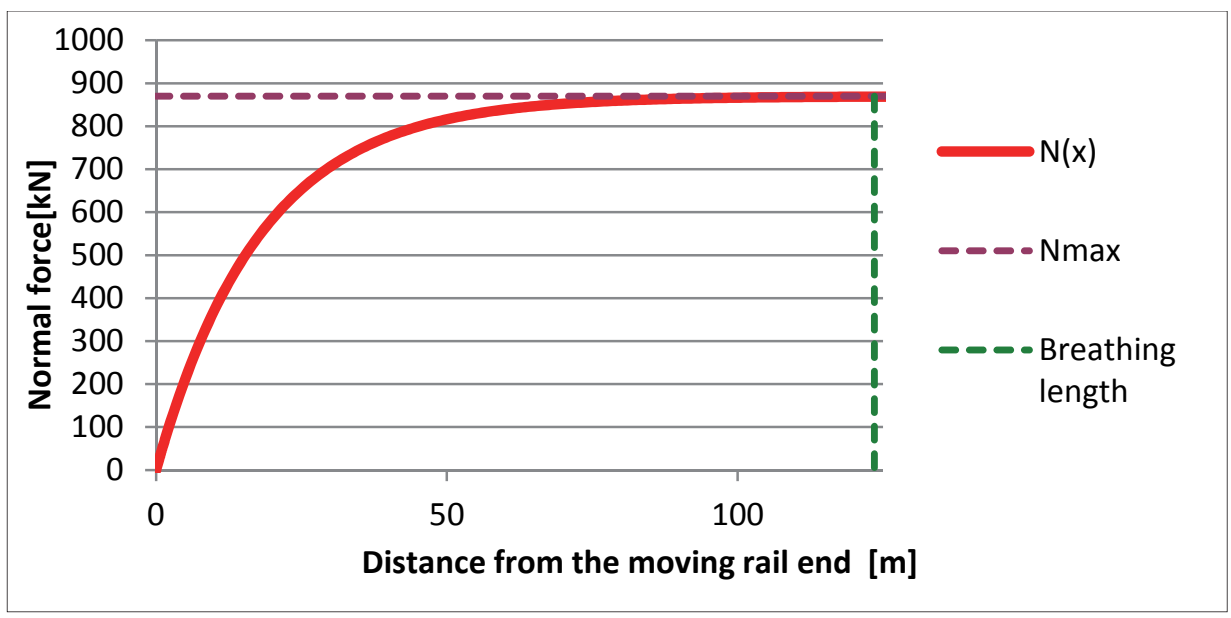

Figure 2. The change of dilatational force along the length of the rail in case of flexible shear resistance

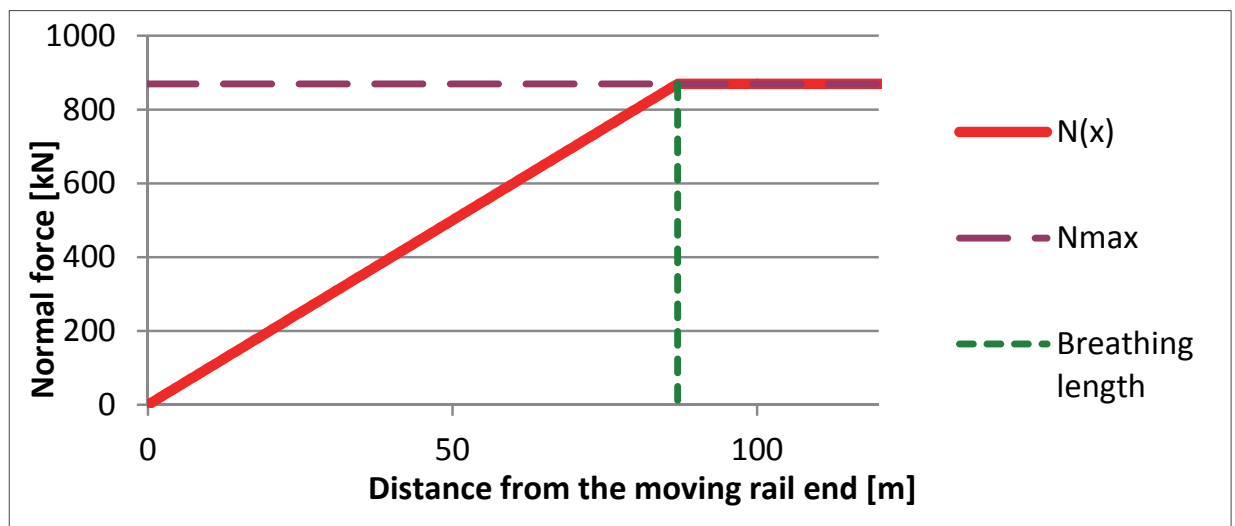

Figure 3. The change of dilatational force along the length of the rail in case of plastic shear resistance 


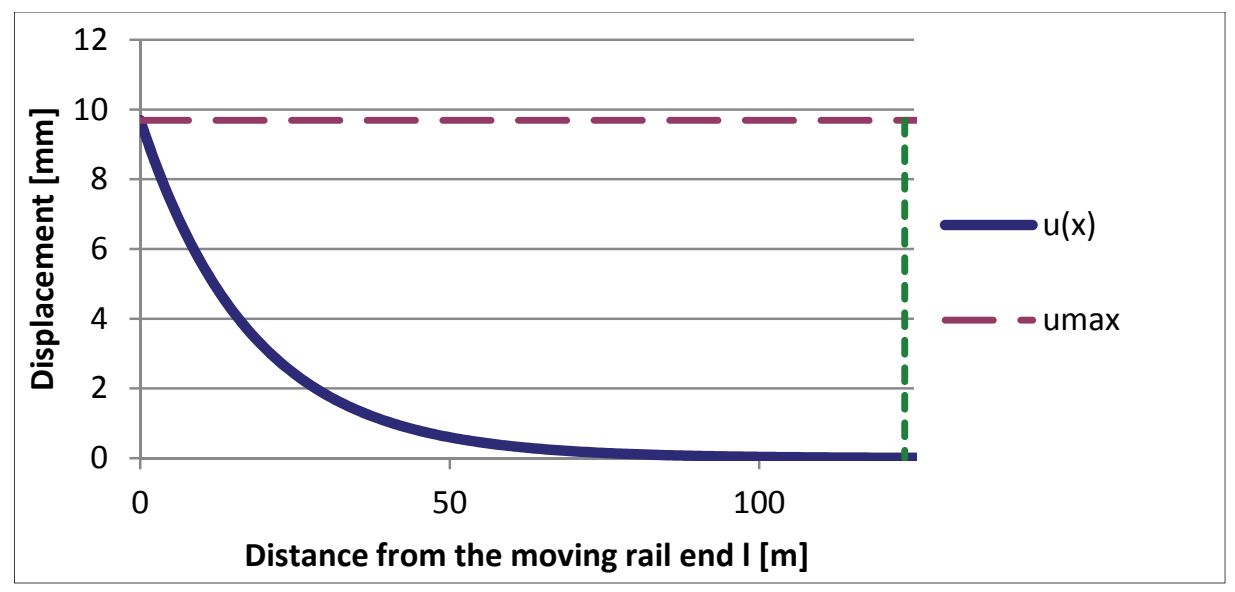

Figure 4. The displacement of the rail along the length of the rail in case of flexible shear resistance

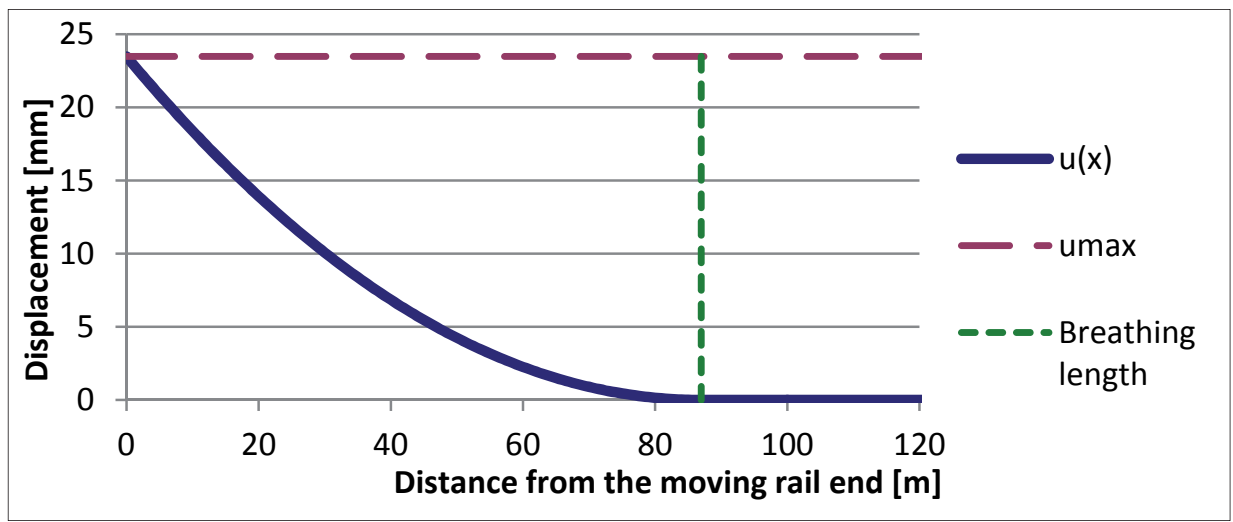

Figure 5. The displacement of the rail along the length of the rail in case of plastic shear resistance

Based on the Figures 2-5 it can be stated that the hypothesis of the linear change of the dilatational force in case of embedded rails can not be applied as in the cases of ballasted tracks and slab tracks with direct rail fastening, and the evolving rail end movements are significantly smaller than the ones expected in ballasted track and slab track with direct rail fastening.

\section{The analytical description of longitudinal behaviour}

A method for the analytical description of longitudinal behaviour can be found in Coenraad Esveld's book titled Modern Railway Track [9]. 
The occuring linear shear resistance is described with the following formula (Equation 1):

$$
\tau=k u,
$$

where:

$\tau$ : flexible shear/sticking resistance $[\mathrm{kN} / \mathrm{m}]$,

$\mathrm{k}$ : longitudinal spring constant $[\mathrm{kN} / \mathrm{m} / \mathrm{m}]$,

u: displacement [m].

The differential equation describing the analysed problem can be given with the following formula (Equation 2):

$$
\frac{d^{2} u}{d x^{2}}-\frac{k}{E A} u=0,
$$

where:

$\mathrm{x}$ : distance from the moving rail end $[\mathrm{m}]$;

E: modulus of elasticity of the rail material $\left[\mathrm{kN} / \mathrm{m}^{2}\right]$;

A: cross sectional area of the rail $\left[\mathrm{m}^{2}\right]$.

After solving the differential equation the following equation (Equation 3) can be received for the displacement along the length of the rail (leaving out the deduction):

$$
\begin{gathered}
u(x)= \pm \frac{\alpha \Delta T}{\mu} e^{-\mu x}, \\
\mu=\sqrt{\frac{k}{E A}},
\end{gathered}
$$

where:

$\alpha$ : linear expansion coefficient of the rail material $\left[1 /{ }^{\circ} \mathrm{C}\right]$,

$\Delta \mathrm{T}$ : change of temperature $\left[{ }^{\circ} \mathrm{C}\right]$.

Formula is valid for normal force change:

$$
N(x)= \pm E A \alpha \Delta T\left(1-e^{-\mu x}\right) .
$$

In engineering practice the analysis of two factors is essential. The first one is the size of the complete moving length of the rail (if there is a rail fracture, the breathing length is examined), the other one is the extent of the displacement of the moving rail end $\left(\mathrm{u}_{\max }\right)$. 
Determining the breathing length in a closed form is impossible on the basis of Equation 5, the value of the maximum displacement can be counted from Equation 6:

$$
u_{\max }=u(0)= \pm \frac{\alpha \Delta T}{\mu}= \pm \frac{\alpha \Delta T}{\sqrt{\frac{k}{E A}}}= \pm \alpha \Delta T \sqrt{\frac{E A}{k}}
$$

An Excel program was prepared on the basis of the above calculation, which can calculate and present the changes of the normal force and displacements along the rail line graphically, and gives the complete moving length of the rail with $u_{\text {lim }}=0.01 \mathrm{~mm}$ limit displacement.

With the purpose of validation the results of this program was compared to the results of a former FEM calculation [10] done at Széchenyi István University. The used material characteristics, spring constant and cross sectional data were in Table 2.

Table 2. Input parameters of the model examined

\begin{tabular}{|c|c|c|}
\hline Parameters & Values & Units \\
\hline $\mathrm{E}$ & 206,000 & {$\left[\mathrm{~N} / \mathrm{mm}^{2}\right]$} \\
\hline $\mathrm{A}$ & 7,247 & {$\left[\mathrm{~mm}^{2}\right]$} \\
\hline$\alpha$ & $1.2 * 10^{-5}$ & {$\left[1 /{ }^{\circ} \mathrm{C}\right]$} \\
\hline$\Delta \mathrm{T}$ & 45 & {$\left[{ }^{\circ} \mathrm{C}\right]$} \\
\hline $\mathrm{k}$ & 10 & {$[\mathrm{kN} / \mathrm{mm} / \mathrm{m}]$} \\
\hline
\end{tabular}

The results are summarized in Table 3 .

Table 3. Results I.

\begin{tabular}{|c|c|c|}
\hline Parameters & Value in [10] literature & Value after Z. Major \\
\hline Nmax [kN] & 806.16 & 806.16 \\
\hline $\operatorname{umax}[\mathrm{mm}]$ & 6.33 & 6.59 \\
\hline $\mathrm{z}[\mathrm{m}]$ & $\sim 60.00$ & 79.50 \\
\hline
\end{tabular}

There is only one significant difference in the breathing length among the results in Table 3. The reason of this is that the technical literature estimated the limit of the breathing length from a figure, it put it to where there is no substantial change in the normal force along the length of the rail, while in the author's Excel program the $\mathrm{u}_{\mathrm{lim}}=0.01 \mathrm{~mm}$ limit displacement sets the limit. Therefore the extent of the normal force at $60 \mathrm{~m}$ in both cases was set. These figures are summarized in Table 4.

Table 4. Results II.

\begin{tabular}{|c|c|c|}
\hline Parameter & Value in [10] literature & Value after Z. Major \\
\hline $\mathrm{N}(60 \mathrm{~m})[\mathrm{kN}]$ & 800.22 & 800.21 \\
\hline
\end{tabular}

It can be seen that the running of the normal force is the same in both cases so the author's Excel program can be used for practical calculations, too. 
In connection with the methods above it can stated that planning needs the purchase / creation of a FEM program or the calculation of relatively complicated interrelations has to be done.

Instead of the former interrelations the author is going to make a suggestion to apply a calculation method which is simpler from an engineering point of view but provides correct results.

\section{Longitudinal behaviour from an engineering viewpoint}

In the previous paragraph the analytical aspect of the dilatational behaviour of the rail in embedded rail structures was decribed, on the basis of which the author deducted the following interrelation (Equation 7):

$$
u_{\max }=u(0)= \pm \frac{\alpha \Delta T}{\mu}= \pm \frac{\alpha \Delta T}{\sqrt{\frac{k}{E A}}}= \pm \alpha \Delta T \sqrt{\frac{E A}{k}} .
$$

Instead of applying the Equation 7 a ,c" system factor for each rail system was defined, and it is used to rewrite the correlation into the following formula (Equation 8):

$$
u_{\max }=u(0)= \pm c \Delta T \sqrt{\frac{1}{k}},
$$

where:

$$
c=\sqrt{\alpha^{2} \cdot E A} .
$$

In the „c" system factor the material features of the rail was contracted which can be considered constant $(\alpha, E)$, and the cross sectional area in each rail profile. (A). In this form the relationship is simpler and the need for calculation is much lower. The introduced correlation makes the calculation of the rail end movement clear and free from the difficulties of transformation.

To determine the factors the written Excel program was used. Table 5 shows an example for , c" system factors belonging to applied rail profiles. Due to content limit all the calculated values will not be given. 12 rail profiles were examined while the method was being created. (Besides flat bottom rails grooved rails were also examined that are applied on light rail systems.)

Table 5. Values of ,c" system factors in case of 54E1 and 60E1 rails

\begin{tabular}{|c|c|}
\hline Rail profile & $\boldsymbol{c}\left[\boldsymbol{k N}^{0,5}{ }^{\circ} \boldsymbol{C}\right]$ \\
\hline $54 \mathrm{E} 1$ & 14.386 \\
\hline $60 \mathrm{E} 1$ & 15.084 \\
\hline
\end{tabular}

Note: During the calculation the modulus of elasticity of the rail material was $\mathrm{E}=206,000 \mathrm{~N} / \mathrm{mm}^{2}$. The linear expansion coefficient was $\alpha=1.2 * 10^{-5}\left[1 /{ }^{\circ} \mathrm{C}\right]$. 
Having done the validation exercise introduced earlier the result below was received (Equation 10):

$$
u_{\max }=u(0)=c \Delta T \sqrt{\frac{1}{k}}=14.662 \times 45 \times \sqrt{\frac{1}{10000}}=\frac{14.662 \times 45}{100}=6.5978 \quad[\mathrm{~mm}]
$$

which matches the author's result.

In order to be able to determine the value of the complete moving length of the rail in the relation of the longitudinal spring constant the power functions is determined describing the change considering the $45^{\circ} \mathrm{C}$ temperature change in the following formula (Equation 11):

$$
z(k)=a k^{b} \quad[m] .
$$

The given general correlation by examining the results from the author's Excel program was received. A power function to the breathing length values determined at a spring constant changing in each rail system was adapted, whose ,a” and „b" parameters are summarized in Table 6.

Fig. 6 shows the relation between the occuring breathing length values in the case of 54E1 rail and the longitudinal spring constant.

The applied formula provides the calculation of the breathing length in a closed form, for which there has not been a possibility before.

Due to content limit all the calculated values will not be given. 12 rail profiles were examined while the method was being created. (Besides flat bottom rails grooved rails are also examined that are applied on light rail systems.)

Table 6. Values of $a$ and b factors of the power functions in case of 54E1 and 60E1 rails

\begin{tabular}{|c|c|c|}
\hline Rail profile & $\boldsymbol{a}$ & $\boldsymbol{b}$ \\
\hline $54 \mathrm{E} 1$ & 15,716 & -0.5763 \\
\hline $60 \mathrm{E} 1$ & 16,598 & -0.5763 \\
\hline
\end{tabular}




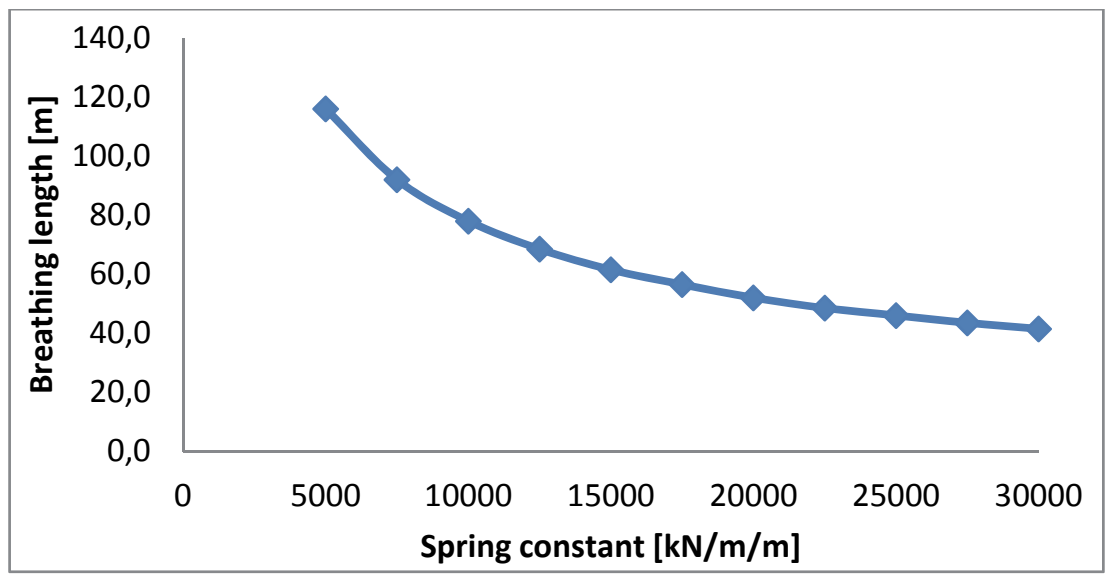

Figure 6. Breathing length occuring in case of $54 E 1$ rail in relation of the spring constant (temperature change is $45^{\circ} \mathrm{C}$ )

Doing the calculation the following result was received (Equation 12):

$$
z(10000,35 G P B)=16,053 \times 10,000^{-0.5762}=79.57 \quad[m],
$$

which result matches the former result. (Table 2)

\section{Summary}

In this article the author presented the creation of a method that makes the calculation and the checking of embedded rails simpler and becomes closer to everyday engineering mentality. The other great advantage of the created method is that it does not require a FEM program, it is time-saving compared to it, because it needs no model-building.

\section{References}

[1] Ludvigh E: Elastic behaviour of continuously embedded rail system. Periodica Polytechnica, 2001.

[2] Nemesdy E: Railway Superstructure. Tankönyvkiadó, Budapest, 1966.

[3] Lichtberger B: Track Compedium. Eurailpress, Hamburg, 2005.

[4] Führer G: Oberbauberechnung, Transpress, Berlin, 1978.

[5] MSZ EN 1991-2:2006: Actions on structures - Traffic loads on bridges.

[6] Major Z: A vasúti híd és vágány kölcsönhatása, Sínek Világa, Budapest, 2012.

[7] Major Z: Special problems of interaction between railway track and bridge, Pollack Periodica, Akadémiai Kiadó, Budapest 2013.

DOI: $\underline{\text { 10.1556/Pollack.8.2013.2.11 }}$

[8] Kormos Gy: Longitudinal behaviour of rail embedded in elastic material. Periodica Polytechnica, 2001.

[9] Esveld C: Modern Railway Track - Second Edition. MRT-Productions, 2001, Zaltbommel, p. 186.

[10] Horvát F, Németh Gy: Technical Report - Edilon type ERS with 35GPB (35LPG) type rail, Győr, 2004. 